\title{
El testeo inicial de los pacientes con infección por COVID-19 tiene una alta tasa de resultados falsamente negativos
}

Initial testing of patients with COVID-19 infection has a high rate of false negative results

\section{Comentado de:}

Arevalo-Rodriguez l, et al. PLoS One. 2020;15(12):e0242958. PMID: $33301459^{1}$

\section{Objetivo}

Revisar y evaluar críticamente la evidencia sobre la tasa de falsos negativos de la reacción en cadena de la polimerasa en tiempo real (RT-PCR, por sus iniciales en inglés) en el testeo inicial para enfermedad por Coronavirus 2019 (COVID-19).

\section{Fuente de datos}

MEDLINE, EMBASE, LILACS, repositorios específicos de COVID-19 -artículos pre-print, registros de ensayos clínicos en curso o recientemente finalizados (clinicaltrials.gov)-; Centro de Coordinación e Información de Evidencia en Políticas y Prácticas (EPPI-Centre); LOVE (Living OVerview of Evidence); Coronavirus Open Access Project Living Evidence Database, y base de datos de publicaciones sobre COVID-19 de la Organización Mundial de la Salud.

\section{Selección de estudios}

Fuero incluidos estudios observacionales de pacientes con sospecha de infección o nexo epidemiológico con un testeo inicial negativo para la detección del ácido ribonucleico (ARN) de coronavirus de tipo 2 causante del síndrome respiratorio agudo severo (SARS-CoV-2) por RT-PCR y con confirmación de infección por una segunda RT-PCR.

No se consideró límite de edad, sexo o lugar del estudio. Fueron incluidos todos los tipos de kits de RT-PCR. Fueron excluidos los estudios que habían sido realizados en otras poblaciones (muestras en vez de pacientes; monitoreo y alta de pacientes con COVID-19); los estudios sin información numérica clara y los realizados para validar nuevas técnicas diagnósticas.

\section{Extracción de datos}

Los datos fueron extraídos por dos revisores independientes. La calidad metodológica fue evaluada por medio de la herramienta QUADAS-2 (del inglés Quality Assessment of Diagnostic Accuracy Studies) para pruebas y procedimientos diagnósticos, que mediante la identificación de cuatro dominios clave facilita la evaluación del riesgo de sesgo, su calificación, y aspectos concernientes a la aplicabilidad para estudios en los que la prueba de referencia se basa en el tiempo seguimiento. La certeza de la evidencia sobre los casos falsos negativos se evaluó según los criterios GRADE.

Se calculó la proporción de resultados falsos negativos, considerando a estos como los casos inicialmente considerados negativos por RT-PCR. El denominador fue el número total de infeccio- nes por SARS-CoV-2 detectados mediante una RT-PCR adicional usando la misma prueba o una diferente. Fueron expresados los hallazgos numéricos cada 100 personas testeadas de acuerdo con tres estimadores de prevalencia de la enfermedad.

\section{Resultados Principales}

Fueron incluidos 34 estudios que habían enrolado 12.057 casos confirmados de COVID-19. Todos los estudios estuvieron afectados por riesgo de sesgo y problemas de aplicabilidad, y se encontró heterogeneidad en la forma de la obtención de la muestra y en el tiempo desde el inicio de los síntomas y su toma. Dado que no pudo realizarse un estimador global representativo de la proporción de falsos negativos, se calcularon los intervalos de predicción del $90 \%$ para incluir la variabilidad entre los estudios, que oscilaron entre 0,02 y 0,54. Este intervalo representa el rango de la proporción de falsos negativos que podría esperarse en el $90 \%$ de los escenarios futuros comparables con los incluidos en este meta-análisis. En la Tabla 1 se muestra el rango de la tasa de falsos negativos en una población de 100 individuos testeados, de acuerdo con tres niveles de prevalencia. Con una prevalencia del $50 \%$ se estimó que 1 de cada 27 casos serían incorrectamente clasificados como negativos.

Tabla 1. Tasa de resultados falsos negativos de acuerdo a la prevalencia de infección de la muestra

\begin{tabular}{|l|c|c|c|}
\hline Prevalencia de infección & $10 \%$ & $30 \%$ & $50 \%$ \\
\hline $\begin{array}{l}\text { Tasa de resultados falsos } \\
\text { negativos }\end{array}$ & 0 a $5 \%$ & 1 a $16 \%$ & 1 a $27 \%$ \\
\hline
\end{tabular}

\section{Conclusión}

Existe una gran heterogeneidad en la proporción de resultados falsos negativos mediante detección de COVID-19 por RT-PCR La evidencia disponible tiene limitaciones, que incluyen un importante riesgo de sesgo y problemas respecto a su aplicabilidad. Sin embargo, es necesario repetir el testeo en pacientes con sospecha de infección por SARS-Cov-2, ya que hasta el $54 \%$ de los pacientes con COVID-19 pueden tener inicialmente un resultado negativo.

Fuente de financiamiento/Conflicto de interés de los autores: Los autores declararon no haber recibido financiamiento específico para realizar este trabajo, ni haber presentado conflictos de interés.

\section{Comentario}

Conocer la tasa de falsos negativos en los resultados de las pruebas de RT-PCR es relevante para la práctica clínica actual. Una incorrecta clasificación de un paciente con COVID-19 como falso negativo tiene consecuencias negativas para la salud pública y para el paciente individual, debido a la falta de identificación de un caso que debe ser aislado para disminuir la circulación viral y por el riesgo de evolución desfavorable al no recibir el tratamiento médico adecuado. Dentro de las 
limitaciones de la evidencia proporcionada por este meta-ánalisis se encuentra la gran variabilidad entre las estimaciones de los estudios incluidos, lo que dificulta la interpretación del estimador global de la proporción de resultados falsos negativos y por lo tanto, la aplicabilidad de estsea información.

Otra revisión reciente documentó además que la probabilidad de una prueba positiva disminuye con el tiempo desde el inicio de los síntomas, y que las muestras orofaríngeas tienen mayor tasa de fasos positivos que las muestras nasofaríngeas. Sin embargo, la probabilidad de observar resultados falsos negativos se redujo considerablemente al repetir la prueba a las 24 horas $^{2}$.

\section{Conclusiones de la comentadora}

Más allá de que una posterior actualización de esta revisión -cuando se cuente con estudios adicionales- pueda arrojar resultados diferentes en términos de una mayor sensibilidad de las pruebas de RT-PCR, por el momento debe considerarse la posibilidad de un resultado falso negativo ante un paciente con sospecha de infección por COVID-19, y volver a testearlo a las 24 horas si esta sospecha lo amerita y/o su resultado implicará alguna toma de decisión con repercusión clínica y/o epidemiológica.

Vanina Pagotto [ Departamento de Investigación, Hospital Italiano de Buenos Aires. vanina.pagotto@hospitalitaliano.org.ar ]

Pagotto V. El testeo inicial de los pacientes con infección por COVID-19 tiene una alta tasa de resultados falsamente negativos. Evid Actual Pract Ambul. 2021;24(1):e002114. Comentado de: Arevalo-Rodriguez I, et al. False-negative results of initial RT-PCR assays for COVID-19: A systematic review. PLoS One. 2020;15(12):e0242958. PMID: 33301459

\section{Referencias}

1. Arevalo-Rodriguez I, Buitrago-Garcia D, Simancas-Racines D, et al. False-negative results of initial RT-PCR assays for COVID-19: A systematic review. PLoS One. 2020;15(12):e0242958. Available from: 10.1371/journal.pone.0242958.

2. Wikramaratna PS, Paton RS, Ghafari M, et al. Estimating the false-negative test probability of SARS-CoV-2 by RT-PCR. Euro Surveill. 2020;25(50):2000568. Available from: 10.2807/1560-7917.ES.2020.25.50.2000568. 